\title{
Educational Status in Bilateral Prelingual Deaf Children with Cochlear Implantation
}

\author{
Seong Hoon Bae, Sang Hyun Kwak, Gi-Sung Nam, and Jae Young Choi \\ Department of Otorhinolaryngology, Yonsei University College of Medicine, Seoul, Korea
}

Received December 11, 2018

Revised January 21, 2019

Accepted January 24, 2019

\section{Address for correspondence Jae Young Choi, MD, PhD Department of Otorhinolaryngology, Yonsei University College of Medicine, 50-1 Yonsei-ro, Seodaemun-gu, Seoul 03722, Korea \\ Tel $+82-2-2228-3484$ \\ Fax +82-2-393-0580 \\ E-mail jychoi@yuhs.ac}

Background and Objectives: This study was undertaken to investigate the educational status in bilateral prelingual deaf children with a cochlear implant (CI), also known as early cochlear implantees (Cls). Type of schooling and enrollment rate of tertiary education were analyzed as primary results. Subjects and Methods: Participants in this study comprised a highly homogeneous group of deaf patients who underwent cochlear implantation at a similar age. Sixty-four Korean patients were enrolled. Statistical data for disabled populations and the general population were obtained from the National Statistics Korea. Results: Among 64 patients, 46, 8, and 10 attended mainstream, integrated, and special schools, respectively. Notably, there was a significant difference in the type of school between hearing-impaired and $\mathrm{Cl}$ groups $(p=0.007)$. Ten of 13 patients enrolled in tertiary education. Conclusions: $\mathrm{Cl}$ users were more likely than hearing impaired students to attend mainstream school. The enrollment rate of $\mathrm{Cl}$ users in tertiary education was the same as that of the general population.

J Audiol Otol 2019;23(3):135-139 Hearing loss.

\section{Introduction}

Cochlear implant (CI) has helped a large number of deaf patients. Because of the large number of studies that have been conducted previously, the indication for CI has become wider, and consequently more patients are eligible for this treatment approach. CI has become more functional with the development of technology, nevertheless it is difficult to determine whether implantees have same abilities as persons with normal hearing, especially from an educational point of view.

In recent years, long-term followed studies of cochlear implantees (CIs) have begun to be published. In 2008, Huber, et al. [1] reported that 52 patients with CI (mean operation age: 5.2 years old) had reached similar level of education to the general population; in 2010, Venail, et al. [2] reported that a survey of 100 prelingual deaf patients who underwent

This is an Open Access article distributed under the terms of the Creative Commons Attribution Non-Commercial License (https://creativecommons.org/licenses/by-nc/4.0/) which permits unrestricted non-commercial use, distribution, and reproduction in any medium, provided the original work is properly cited. surgery under the age of 6 showed a similar result. Finally, in 2017, Illg, et al. [3] demonstrated that CIs achieved a higher level of education than untreated hearing loss patients, but a lower than that of the general population.

The Republic of Korea has the highest percentage of high school graduates in the world (98\% of those ages 25-34) because of compulsory education through high school. In addition, the percentage of enrollment in university education (tertiary education) of high school graduating grade students is $70 \%$, which is also the highest worldwide [4]. Similar to the general population, parents of hearing impaired children want their child to have the same level of education as children with normal hearing.

The purpose of this study was to investigate the schooling status in prelingual-bilateral deaf CIs who underwent surgery prior to 4 years of age. Importantly, the subjects of this study were highly homogenous in terms of age at the time of surgery, as well as the type of deafness. Educational status can be indicative of the abilities and limits of CI. 


\section{Subjects and Methods}

\section{Participants}

Prelingual, bilateral deaf patients without agenesis of cochlear or cochlear nerve who underwent CI surgery before the age of 48 months in Severance Hospital (Seoul, Korea) were included. For long-term follow-up study, we included patients who underwent surgery between 1998 and 2010. There were 124 eligible patients; the survey was conducted by telephone, and 77 caregivers responded. Sixty-four patients were daily CI user, while 13 patients were non- or partial CI user (informed from questionnaire 1). Thirteen non/partial CI users and 47 non responders were excluded from the study, and 64 patients were enrolled. Notably, patients with additional diseases were not excluded because statistic data from National Statistics Korea also include multi-handicapped. Demographic data of patients were shown in Table 1.

Control groups of this study are 'disabled', 'hearing impaired', and 'general population'. Data of each group were taken from statistical reports of National Statistics Korea. 'Disabled' refers to persons with any disabilities registered with the Korean government, including hearing impairment.

Table 1. Demographic data of enrolled patients

\begin{tabular}{lc}
\hline & Enrolled patients \\
\hline Sex (n, \%) & $34(53.1)$ \\
Male & $30(46.9)$ \\
Female & $8-23$ (Mean 14.8) \\
Age (years) & $1-3$ (Mean 1.89) \\
Age of implant (years) & \\
Caregiver (n, \%) & $53(83.0)$ \\
Both & $4(6.0)$ \\
Single & $7(11.0)$ \\
Unanswered & \\
Additional disabilities (n, \%) & $4(6.3)$ \\
With DD & $5(7.8)$ \\
Without DD & $55(85.9)$ \\
None & \\
Etiology & 54 \\
Non-syndromic hearing loss with & \\
unidentified etiology & 3 \\
Pendred syndrome & 1 \\
Kabuki syndrome & 1 \\
CHARGE syndrome & 1 \\
Congenital CMV infection & 1 \\
Unknown syndromic hearing loss & 1 \\
Noonan syndrome & 1 \\
Meningitis & 1 \\
Waardenburg syndrome & \\
\hline DD: delayed mental development, CMV: cytomegalovirus
\end{tabular}

136 J Audiol Otol 2019;23(3):135-139
'Hearing-impaired' group refers to persons with hearing impairment registered with the Korean government, including CI implantees [5]. 'General population' refers to persons attending mainstream and integrated school with no registered disabilities.

Written informed consents were obtained and this study protocol was approved by the Institutional Review Board of Yonsei University College of Medicine (IRB No.4-20180617).

\section{Materials}

A survey of caregivers of CIs was conducted by telephone, in combination with a retrospective medical chart review.

Questions contained in the survey were as follows:

- Does your child use CI in daily life?

- Who is living with your child?

-What type of school does (did) your child attend?

- Did your child enter university or college?

Retrospective chart review was used to gather the following data:

- Patient's age and sex

- Patient's date of birth and CI operation

- Patient's comorbidities

\section{Statistical analysis}

All statistical analysis was performed by using IBM SPSS 23.0 software (IBM Corp., Armonk, NY, USA). The comparisons between groups were assessed by the chi-squared test and Fisher's exact test. Significance was indicated by $p<0.05$. Because the number of subgroups "integrated school" were too small, a statistical comparison was conducted between mainstream school and other types of school (integrated and special).

\section{Korean educational system for disabilities}

The Korean educational system consists of three types of schools. First, mainstream schools educate the general population of students in Korea. Next, integrated schools which educate the general population of students and minor disabled students who can adequately maintain the pace of several classes with the general population of students. Here, disabled students move to special classes when they required specific educational support. Finally, special schools solely educated disabled students. Korean students are required to attend high school, but their caregivers can choose the type of school that the students must attend. After graduation from high school, students can apply for college or university acceptance if they achieve a certain academic level on a nationwide test. 


\section{Results}

\section{Schooling of Cls}

All 64 enrolled patients provided information regarding the schooling situations of the patients. The data of the " $\mathrm{Cl}$ " group are the results from CIs who were enrolled in this study. The schooling data and demographic data of the control groups were taken from the 2014 statistical report of the National Statistics Korea. Age of control groups was from 8 to 19 years old, male to female ratio was approximately $2: 1$ in 'Disabled' and 3:2 in 'Hearing impaired' group. The proportion of 'Hearing impaired' in 'Disabled' was 3.5\%. Notably, $55 \%$ of 'Hearing impaired' group have a history of CI surgery including unused devices [5].

Among 64 patients in ' $\mathrm{CI}$ ' group, 46, 8, and 10 attended mainstream, integrated, and special schools, respectively. Notably, there was a significant difference in the types of schools between 'Hearing impaired' and 'Cl' groups ( $p=0.007)$. There were also significant differences between the "Disabled" group and the other groups (Fig. 1).

\section{Tertiary education of Cls}

The rates of entry to tertiary educational institutions of students in the 'General population' (68.9\%) and 'Disabled' (46.3\%) were obtained from the 2014 statistical report of the National Statistics Korea [6]. Age of control groups was 19 years old, and male to female ratio of 'Disabled' and 'General population' were approximately $2: 1$ and $1: 1$, respectively. However, the rate of entry to tertiary educational institutions of 'Hearing impaired' group was not investigated. Among the

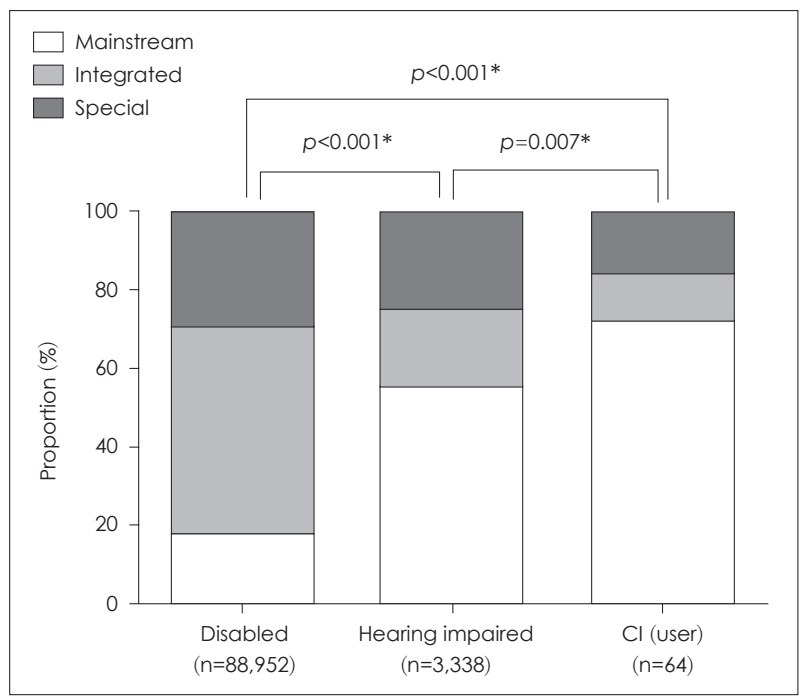

Fig. 1. Schooling type compared with other disabled children. Disabled group includes hearing impaired group. Statistical analysis was conducted by Fisher's exact test. *Statistical significance $(p<$ 0.05). Cl: cochlear implant.
64 patients in 'Cl' group, only 13 patients were over 19 years old and eligible to enter a tertiary educational institution. Ten patients had entered university or college and 3 were employed. There was no significant difference in the rates of entry to tertiary educational institutions among $\mathrm{CI}$ and general population groups (Fig. 2).

\section{Discussion}

Previously, there have been reports regarding the educational status of CIs, which frequently reported that CIs are more educated than non-implanted hearing-impaired individuals but less educated than the general population [1-3]. The results in the current study were similar, even with stricter enrollment criteria than previous literature to control confounding factors. CIs tended to attend mainstream school at higher rates than hearing-impaired and other disabled individuals. The type of high school education in Fig. 1, levels of education are stratified as Special, Integrated, and Mainstream schools. Consequently, we can estimate students' learning abilities on the basis of the type of schooling that they attend, assuming that desire of education is similar in population. In Fig. 2, "CI" group showed nearly identical rates of tertiary education enrollment, compared with the general population. Even though comparison with 'Hearing impaired' was impossible due to lack of data, Fig. 2 implies CI implantees are eligible for tertiary education as well as general population.

There could be confounding factors which affected the educational status of enrolled patients even though the participants are highly homogeneous in the type of deafness and

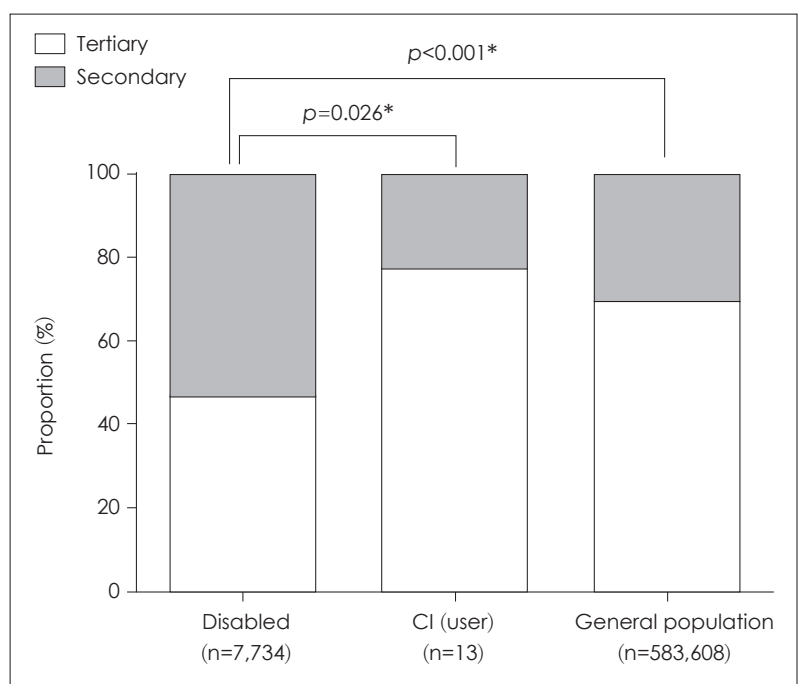

Fig. 2. The rate of enrollment in tertiary education. Data of 'Disabled' and 'General population' describe senior-grade high school students in Korea. Statistical analysis was conducted by Fisher's exact test. *Statistical significance $(p<0.05)$. Cl: cochlear implant. 
age at implantation. The most important variable is the age at the operation, with evidence from numerous studies [7-9]. In this study, age at the operation was controlled by enrollment criteria of under 48 months. However recent studies reported the better outcome of CI in patients who operated at the age under 24 months or even earlier [7,10]. Nevertheless, we had to expand enrollment criteria to 48 months at surgery because of ensuring statistical significance and the small number of patients. In addition, CI surgery has not been generalized before the 21th century in Korea especially in children under 24 months. Socioeconomic status of the family is also thought to be an important factor $[11,12]$. Percentage of the family with both parents in "hearing impaired" group was $83.5-88.9 \%$ according to the statistical report of the National Statistics Korea [13]. Compare to participants in this study (93\%), family status possibly affected the result of the study. However, given that all surgeries were supported by governmental health insurance, it seems less likely that economic status affected result significantly. Additional disabilities can be confounding factors also, however, according to statistical report of the National Statistics Korea, the rate of additional disability in "hearing impaired" group was $17.0 \%$ and rate of additional delayed mental development was 3.3\%. This is not much different from or even lower than participants of this study, $14.1 \%$, and $6.3 \%$, respectively [14].

The small number of participants is another limitation of this study. In addition, it caused elongation of enrollment period to 12 years. Although there was no revolutionary development of the CI technique in this period, it is nevertheless possible to doubt biased results. Finally, this was a retrospective study with no controlled group, consequently, data of the control group was taken from other reports. Even though the reports from the National Statistics Korea is credible, bias and incompleteness would be present inevitably. For example, because there was no data of 'hearing impaired' group, impacts of CI in tertiary education enrollment could not be evaluated directly. There is a possibility that hearing impairment itself is also not a limiting factor for entry to tertiary education. In the future, we expect additional data regarding vocational status, as well as greater numbers of patients.

In conclusion, prelingual bilateral deaf children who operated $\mathrm{CI}$ before 4 years old have the benefit in terms of education. They are more likely to attend mainstream schools than general hearing-impaired population; further, they enroll in tertiary education at similar rates to those of the students in the general population.

\section{Conflicts of interest}

The authors have no financial conflicts of interest.

\section{Author Contributions}

Conceptualization: Jae Young Choi. Data curation: Seong Hoon Bae, Sang Hyun Kwak, and Gi Sung Nam. Formal analysis: Seong Hoon Bae. Methodology: Jae Young Choi. Project administration: Seong Hoon Bae. Resources: Jae Young Choi. Software: Seong Hoon Bae. Supervision: Jae Yong Choi. Validation: Seong Hoon Bae and Jae Young Choi. Visualization: Seong Hoon Bae. Writing — original drift: Seong Hoon Bae. Writing — review \& editing: Seong Hoon Bae and Jae Young Choi.

\section{ORCID iDs}

Seong Hoon Bae

Sang Hyun Kwak

Gi-Sung Nam

Jae Young Choi

https://orcid.org/0000-0001-9243-9392

https://orcid.org/0000-0002-2827-8456

https://orcid.org/0000-0002-8392-5759

https://orcid.org/0000-0001-9493-3458

\section{REFERENCES}

1) Huber M, Wolfgang H, Klaus A. Education and training of young people who grew up with cochlear implants. Int J Pediatr Otorhinolaryngol 2008;72:1393-403.

2) Venail F, Vieu A, Artieres F, Mondain M, Uziel A. Educational and employment achievements in prelingually deaf children who receive cochlear implants. Arch Otolaryngol Head Neck Surg 2010;136:36672.

3) Illg A, Haack M, Lesinski-Schiedat A, Büchner A, Lenarz T. Longterm outcomes, education, and occupational level in cochlear implant recipients who were implanted in childhood. Ear Hear 2017; 38:577-87.

4) Organization for Economic Cooperation and Development (OECD). Education at a Glance 2017 [Internet]. Paris: OECD; 2017 [cited 2018 May 27]. Available from: URL: http://dx.doi.org/10.1787/eag-2017-en.

5) Korean Statistical Information Service (KOSIS). Status of special education subjects [Internet]. Daejeon: KOSIS; 2016 [cited 2018 May 27]. Available from: URL: http://kosis.kr/statHtml/statHtml.do?mode =tab\&orgId=112\&tblId=DT_11214_2014A009\&vw_cd=MT_ZTITLE\&

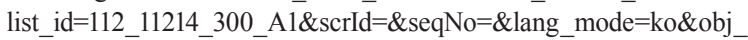
var_id $=\& i t m \_i d=\&$ conn_path $=$ MT_ZTITLE\&path $=\% 252$ Fstatistics List $\% 252$ FstatisticsListIndex.do.

6) Korean Statistical Information Service (KOSIS). Career direction after high school graduation [Internet]. Daejeon: KOSIS; 2016 [cited 2018 May 27]. Available from: URL: http://kosis.kr/statHtml/statHt$\mathrm{ml}$.do? mode $=$ tab\&orgId=112\&tblId=DT_11214_2014A024\&vw $\mathrm{cd}=\mathrm{MT} \_Z T I T L E \& l i s t \_\mathrm{id}=112 \_11214 \_300 \_\mathrm{A} 1 \& \mathrm{scrId}=\& \mathrm{seqNo}=$ \&lang_mode $=$ ko\&obj_var_id $=\overline{\text { \&itm_id }}=\&$ conn_path $=$ MT_ZTITL E\&path $=\% 252$ FstatisticsList $\% 252$ FstatisticsListIndex.do.

7) Ching TYC, Dillon H, Leigh G, Cupples L. Learning from the Longitudinal Outcomes of Children with Hearing Impairment (LOCHI) study: summary of 5-year findings and implications. Int J Audiol 2018;57(sup2):S105-11.

8) Goh BS, Fadzilah N, Abdullah A, Othman BF, Umat C. Long-term outcomes of universiti Kebangsaan Malaysia cochlear implant program among pediatric implantees. Int J Pediatr Otorhinolaryngol 2018;105:27-32.

9) Incerti PV, Ching TYC, Hou S, Van Buynder P, Flynn C, Cowan R. Programming characteristics of cochlear implants in children: effects of aetiology and age at implantation. Int J Audiol 2018;57:S27-40.

10) Bruijnzeel H, Ziylan F, Stegeman I, Topsakal V, Grolman W. A systematic review to define the speech and language benefit of early ( $<12$ months) pediatric cochlear implantation. Audiol Neurootol 2016;21:113-26.

11) Davis-Kean PE. The influence of parent education and family income on child achievement: the indirect role of parental expectations 
and the home environment. J Fam Psychol 2005;19:294-304.

12) DesJardin JL, Eisenberg LS. Maternal contributions: supporting language development in young children with cochlear implants. Ear Hear 2007;28:456-69.

13) Korean Statistical Information Service (KOSIS). Family members of disabled students [Internet]. Daejeon: KOSIS; 2016 [cited 2018 May 27]. Available from: URL: http://kosis.kr/statHtml/statHtml.do? mode=tab\&orgId $=112 \&$ tblId $=$ DT $11214 \quad 2014$ A062\&vw cd $=$ MT ZTITLE\&list_id $=112 \_11214 \_300 \_A 1 \&$ scrId $=\&$ seqNo $=\& l a n g$ mode $=$ ko\&obj var $\mathrm{id}=\& \mathrm{itm}$ id=\&conn path=MT ZTITLE\&path $=\% 252$ FstatisticsList $\% 252$ FstatisticsListIndex.do.

14) Korean Statistical Information Service (KOSIS). Status of additional disability in disabled students [Internet]. Daejeon: KOSIS; 2016 [cited 2018 May 27]. Available from: URL: http://kosis.kr/statHtml/statHt$\mathrm{ml} . \mathrm{do}$ ? $m o d e=$ tab\&orgId $=112 \&$ tblId $=$ DT_11214_2014A057\&vw_ cd=MT_ZTITLE\&list_id $=112 \_11214 \_300 \_A 1 \& \operatorname{scrId}=\& \operatorname{seqNo}=$ \&lang_mode $=$ ko\&obj_var_id $=\& i t m \_i d=\& c o n n \_p a t h=M T \_Z T I T L$ E\&path $=\% 252$ FstatisticsList $\% 252$ FstatisticsListIndex.do. 